Supplement of Hydrol. Earth Syst. Sci., 22, 3639-3662, 2018

https://doi.org/10.5194/hess-22-3639-2018-supplement

(C) Author(s) 2018. This work is distributed under

the Creative Commons Attribution 4.0 License.

(c) (1)

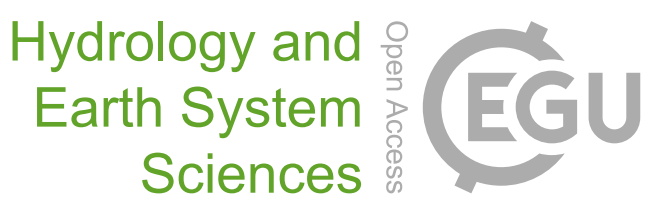

Supplement of

\title{
Ecohydrological particle model based on representative domains
}

Conrad Jackisch and Erwin Zehe

Correspondence to: Conrad Jackisch (jackisch@kit.edu)

The copyright of individual parts of the supplement might differ from the CC BY 4.0 License. 
Simulation of the irrigation experiment using echoRD at a loess site (Weiherbach basin, SW Germany)

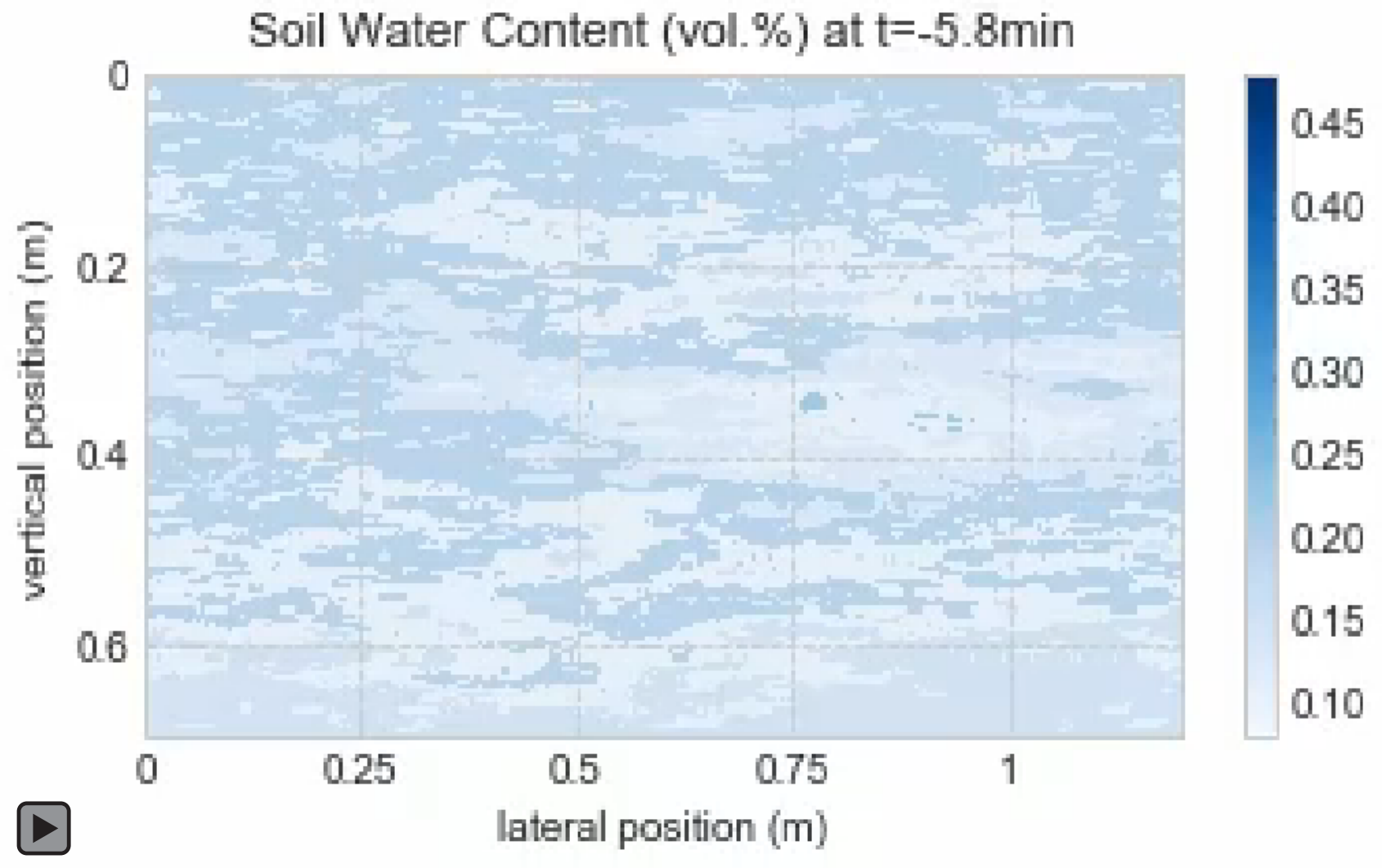

